\title{
НЕОБХОДИМОСТЬ РАЗВИТИЯ МЕНЕДЖЕРСКИХ СПОСОБНОСТЕЙ ВЫПУСКНИКОВ ВУЗА В КОНТЕКСТЕ ПРИОБРЕТЕНИЯ ИНТЕЛЛЕКТУАЛЬНОГО РЕСУРСА, ПЕРЕХОДЯЩЕГО В ИНТЕЛЛЕКТУАЛЬНЫЙ КАПИТАЛ
}

\author{
Наджафов Ильгар Айдынович \\ к.П.н., доцент \\ Курский институт кооперации \\ филиал АНО ВО «Белгородский университет \\ кооперации, экономики и права»
}

Аннотация: Статья содержит перечень методических разработок для новаторской группы, семинаров и ролевых инсценировок с функциональным дискурсом специалистов, чья профессиональная деятельность требует менеджерских способностей. В статье рассматривается необходимость использования менеджерских способностей как важного фактора управления в новых условиях рыночной экономики. Определены менеджерские способности в контексте превращения интеллектуального ресурса в интеллектуальный капитал. Выстроен действенный механизм педагогической технологии к программе повышения квалификации «Формирование навыков аргументатора дискуссий на русском и английском языках». Статья предназначена для педагогов-практиков, студентов и аспирантов - будущих управленцев, дипломатов, журналистов, конфликтологов, юристов и PRспециалистов.

Ключевые слова: интеллектуальный капитал, интеллектуальные ресурсы, новаторская группа, менеджерские способности, функциональный дискурс.

\section{THE NEED TO DEVELOP THE MANAGERIAL SKILLS OF UNIVERSITY GRADUATES IN THE CONTEXT OF INTELLECTUAL RESOURCE ACQUISITION, TURNING INTO INTELLECTUAL CAPITAL}

Najafov Ilgar Ajdinovic

\begin{abstract}
The article contains a list of methodological developments for the innovative group, seminars and role-plays with functional discourse of specialists
\end{abstract}


whose professional activity requires managerial skills. The article considers the need to use managerial skills as an important factor of management in the new conditions of the market economy. Managerial skills are identified in the context of transformation of intellectual potential into intellectual capital. The effective mechanism of pedagogical technology to the program of professional development "Formation of skills of the argumentator of discussions in Russian and English" is built. This article is intended for educators, practitioners, students and postgraduate students - future managers, diplomats, journalists, conflict resolution specialists, lawyers and PR specialists.

Key words: intellectual capital, intellectual resources, innovative group, managerial abilities, functional discourse.

Искусство убедительно выражать идеи и мысли, пробуждая разум людей для совершенствования личной и профессиональной жизни, является важным компонентом менеджерской деятельности. Учитывая то, что специалист в области управления должен участвовать в международных конференциях и вести деловые переговоры с зарубежными бизнесменами, дискурс менеджера включает навыки устной и письменной речи в сфере делового общения на английском языке. Поэтому развитие менеджерских способностей реализуется в контексте интеллектуального ресурса, включающего коммуникативный контакт, взаимопонимание, успешное речевое общение и аргументацию.

Современное обучение студентов иностранному языку определяется новым этапом развития образования, связанного с социальноэкономическими и политическими преобразованиями в обществе, выдвигающими требования к формированию нового типа мышления, связанного с такими понятиями как «интеллектуальный ресурс», «интеллектуальный капитал». Приобретение знаний определяется следующими факторами:

студент вуза должен стремиться получить не только знания посредством лекционных и практических занятий, но и уметь самостоятельно добывать их;

учитывать требования работодателей, которым нужны умения нестандартно и творчески мыслить, работать в команде, умение искать необходимую для решения проблемы информацию; 
* учитывать, что критерием отбора лучших студенческих работ является общая эрудиция, креативность, коммуникабельность, лидерский потенциал и инновативность [6];

* совершенствовать качество знаний в контексте превращения интеллектуального ресурса в интеллектуальный капитал.

Студенту должно быть ясно, что его образовательная деятельность вносит в научный процесс вуза тот результат, который определяет его эффективность и конкурентоспособность.

Механизм реализации данных факторов входит в образовательную деятельность педагогов-менеджеров, настроенных на новое мышление, на неприемлемость дилетантского подхода к приобретению знаний и способного к подготовке личности профессионала, умеющего превращать свои знания в интеллектуальный капитал [4]. Преподаватель-менеджер создает программы управления интеллектуальными ресурсами, изначально учитывая потребности рынка, четкие требования и мотивы бизнеса. Следует отметить, что ключевым элементом программы является ее фундамент - работа по обмену знаниями и определение знаний, необходимых для продажи, превращение мыслительно-информационной деятельности каждого в нужный и продаваемый капитал. Никто «не стоит в сторонке»[5] - все задействованы в поиске информации, в дискуссионном обсуждении, в исследовании, в создании проектов, в дополнительном обучении.

Распространение знаний осуществляется в тесном сотрудничестве студентов и преподавателей. В эпицентре изменений находятся преподаватели, которые могут на специальных семинарских занятиях в вузе научить навыкам управления интеллектуальными ресурсами и пониманию новых требований, происходящих в экономике и международных отношениях.

Следует отметить, что на нашу идею необходимости развития менеджерских способностей выпускников вуза, в контексте приобретения интеллектуального ресурса, переходящего в интеллектуальный капитал, повлияли исследования известных ученых о современных проблемах менеджмента, лингвистики, новых методах и прикладных средствах менеджмента, HR-менеджмент, использование новых технологий государственного и муниципального управления. Среди них - Мильнер Б.З., д.э.н., профессор; Кибрик А.А., д.ф.н., профессор; Мищенко Л.И., д.п.н., профессор. 
Практические занятия, проводимые на курсах дискуссионноаргументативного общения по специальной программе и темам, составленным на русском и английском языках, показали, что учебная дискуссия может быть средством развития менеджерских способностей, включающих знания принципов успешного речевого общения и аргументации. Дискуссионная модель, формируя профессиональносоциальные мотивы, развивает понимание студентами возможности преобразования интеллектуального ресурса в интеллектуальный капитал.

Мыслительные действия, вызванные стратегией дискуссий и аргументаций, умения и способности, развиваемые в процессе дискуссионной работы, дискуссионного общения на двух языках, формируются в следующей составляющей развития менеджерских способностей:

* способность мыслить оперативно и конструктивно, обеспечивая прогнозирование противоположного высказывания [5];

* способность улавливать тонкости русского и английского языков с целью осуществления полноценного обсуждения и устранения недопонимания [6];

* проявление упорства при выполнении преддискуссионной работы (сбор информации, чтение на двух языках);

* стремление к изучению нескольких иностранных языков;

с создание новаторской группы, состоящей из студентов старших курсов;

* консультирование семинарских занятий;

* организация практических занятий по работе с информационными технологиями;

* проведение обучения, объясняющего предназначение баз данных, механизмов поиска и сбора знаний в сотрудничестве с IT-отделом;

* сотрудничество, взаимопонимание, интеллектуально-творческое влияние;

* поддержка - репетиция задачи, компетентная оценка того, что удалось сделать;

* содействие проведению интерактивных дискуссий;

* поиск новых источников информации;

* поступенчатое восхождение к основной цели обучения.

Для развития менеджерских способностей нами применяется методика 
дискуссионно-аргументативного общения на русском и английском языках. В результате данной методики развиваются следующие критерии менеджерских способностей:

владение навыками общения, как на родном, так и на английском языках с соблюдением норм вежливости, коммуникативной ответственности; выбор и использование формул общения в зависимости от статуса общающихся, регистра общения;

* восприятие английского языка как объединяющего фактора;

* «способность формировать разговорный дискурс то в качестве слушателя, то в качестве говорящего с одним или более собеседником, используя стратегии дискурса и сотрудничества» [2];

* умения четко выразить мысль не только в устном общении, но и в деловой переписке, в реферировании и аннотировании текста по специальности, в планировании дискуссионных сценариев, соблюдая при этом стратегии взаимодействия (интеракции) [8];

* умения отбирать ключевые слова и словосочетания профессиональной тематики, читать и переводить тексты журнальных статей на английском языке;

* умения упорядочивать предложения в единый связный текст в соответствии со схемами взаимодействия;

* умение предлагать нестандартные идеи, стремиться к многоязычию в целях понимания другой культуры и поддержки международных контактов.

Новое осмысление студентами своей учебной деятельности, связанное с требованиями рынка знаний к выпускникам инновационного вуза, вырисовывается в формате следующих технологий:

* самостоятельное составление текстов о способах принятия экономических решений;

* с создание экспериментальных проектов;

* участие в образовательной программе «Формирование навыков аргументатора дискуссий на русском и английском языках»;

* сотрудничество с отделом информационных технологий.

Подготовительная фаза дискуссионных занятий включает сценарии дискуссий, вопросы-стимулы, тесты-проблемы и интерактивные карты. В дискуссионном общении проявляется высший дар мыслительной деятельности. Специальные темы позволяют выявить интересы и развивать навыки и дисциплину максимальной потребности знать и учиться, 
преодолевая трудности. Выявление внутренних мотивов базируется на активном и заинтересованном сотрудничестве преподавателя и учеников, стремлении выявить скрытые способности посредством усложненных в понятийном смысле дискуссионных тем. На занятиях проявляются особые мыслительные действия обучаемого, основанные на высоком уровне осведомленности, создающей огромный запас ресурсов, которые благодаря отличной памяти реализуются незамедлительно.

Вышеназванные управленческие технологии реализуются в новаторской группе, задуманной как дополнительное обучение студентов изменениям, происходящим в экономике, международных отношениях с целью развития такого инновативного мышления, которое будет способствовать пониманию новых требований современных организаций и новой культуры бизнес-структур.

Студентам был предложен проект новаторской группы, цель которой заключается в создании на предприятии менеджерской группы, решающей конфликтные ситуации в формате дискуссий.

Новаторская группа основывается на идее взаимодействия научных знаний с предпринимательской деятельностью, т.е. концепции, изученные на занятиях, будут соотноситься с проблемами «реального мира» [1].

В дальнейшем в новаторской группе планируется обучение предпринимательской деятельности. Семинарские занятия в новаторской группе утверждают принцип, который приветствует инновации всеми возможными способами, который дает студентам шанс предложить свои собственные оригинальные идеи и объясняет, что наступило время эксперимента [4].

В учебной новаторской группе была использована наша технология, функционирующая по следующей схеме: 


\section{Схема 1}

\begin{tabular}{|} 
Новаторская группа студентов, работающих на предприятии, \\
использующая технологию культуры менеджмента для решения \\
конфликтных вопросов в дискуссионном сотрудничестве
\end{tabular}

Исходя из вышеизложенных факторов, менеджерские способности понимаются нами как потребность в общении, в приобретении знаний, 8 умении аргументированно убедить аудиторию на русском и английском языках, в стремлении к успешной профессиональной деятельности и в проявлении творческих способностей. Менеджерские способности рассматриваются нами как необходимость их реализачии в образовательном прочессе для осуществления превращения интеллектуального ресурса в продаваемый $u$ востребованный интеллектуальный капитал. Эффективной реализации этого процесса способствуют функииональные особенности дискуссии.

Учащимся предлагаются следующие темы: «Профессионализм - это требование времени или необходимое стремление к успеху?», «Приобретение знаний - интеллектуальное наслаждение или социальная необходимость?», «Знание иностранных языков - это способ получить хорошую работу или необязательная учебная дисциплина?», «Хорошая работа - высокие доходы на рутинном предприятии или возможность экспериментировать и воплощать в жизнь новые идеи?» 
В самостоятельной преддискуссионной работе учащиеся составляют тексты к ролевой беседе «На рынке труда», собирают информацию о разных профессиях, участвуют в семинаре «Разностилевые функции дискурса менеджера», который позволяет определить особенности функционирования языковых средств, в конкретных условиях их использования.

Выстраивается определенная система управления интеллектуальными ресурсами в вузе в условиях конкурентных преимуществ интеллектуального капитала, и обучение иностранному языку определяется вектором инновационной деятельности преподавателя, способного к подготовке личности профессионала, умеющего превращать свои знания в интеллектуальный капитал [4].

Таким образом, новый взгляд на образование, отражающее «мировую тенденцию комплексной подготовки квалифицированных специалистов с учетом реальных потребностей рынка труда» [4], определяет создание специальных программ, ориентированных на то, чтобы студенты ощутили необходимость развития менеджерских способностей и были готовы к работе в новых условиях преобразования знаний в интеллектуальный капитал.

\section{Список литературы}

1. Интерактивные технологии в иноязычном образовании: исследование стратегий и опыта применения: коллективная монография / под научн. ред. Г.В. Сороковых. - М.: УЦ «Перспектива», 2013. - 172 с.

2. Кибрик А.А. Модус, жанр и другие параметры классификации дискурсов // Вопросы языкознания. - 2009. - № 2.

3. Колношенко О.В. Концепция менеджмента - М.: Изд-во «Экзамен», 2007.

4. Мильнер Б.3. Управление интеллектуальными ресурсами // Вопросы экономики, 2008, №7.

5. Наджафов И.А. Учебная дискуссия как средство формирования профессиональной компетентности будущих специалистов по связям с общественностью Научная монография - Курск: Изд-во МЭБИК, 2010.127с.

6. Наджафов И.А. Приобретение знаний в контексте научноинновационной политики // Известия ЮЗГУ, 2013, №5.

7. Общеевропейские компетенции владения иностранным языком: изучение, обучение, оценка. - Департамент по языковой политике, Страсбург. - 2003. - 256 с. 


\section{References}

1. Interactive technologies in foreign language education: research of strategies and application experience: a collective monograph / under the scientific ed. of G. V. Sorokovykh. - Moscow: UTS "Perspektiva", 2013. - 172 p.

2. Kibrik A. A. Modus, genre and other parameters of classification of discourses / / Questions of linguistics. - 2009. - № 2.

3. Kolnoshenko O. V. The Concept of Management-M.: publishing house "Exam", 2007.

4. Milner B. Z. Management of intellectual resources / / Questions of Economics, 2008, no. 7.

5. Najafov I. A. Educational discussion as a means of forming professional competence of future specialists in public relations scientific monograph - Kursk: MEBIK publishing House, $2010.127 \mathrm{p}$.

6. Najafov I. A. Acquisition of knowledge in the context of science and innovation policy / / Izvestiya YUZGU, 2013, no. 5.

7. Common European competences of foreign language proficiency: study, training, assessment. - Department of language policy, Strasbourg, 2003, 256 p.

(С) И.А. Наджафов, 2020 